$\begin{array}{lllllllllllll}\text { A T A } & \text { C H E M I C A } & \text { S C A N D I N A V I C A } & 25 & (1971) & 379-389\end{array}$

\title{
The Crystal Structure of Glutarimide
}

\author{
C. S. P E T E R S E N
}

Department of Chemistry, University of Oslo, Blindern, Oslo, Norway

\begin{abstract}
The crystal structure of glutarimide has been determined by three-dimensional X-ray analysis. The refinement has been carried out separately on intensity data collected from Weissenberg diagrams and from an automatic four circle diffractometer. The crystals are monoclinic with space group $P 2_{1} / c$ and unit cell parameters $a=10.226$ $\AA, b=7.416 \AA, c=7.300 \AA, \beta=102.28^{\circ}$. The phase problem was solved by direct methods and refined by full-matrix least squares to $R=$ $6.2 \%$. The conformation of the molecule may be described as a halfchair. The atom C3 is out of the plane of the other ring atoms by $0.59 \AA$. In the crystal the molecules are hydrogen bonded such as to form chains running in the direction of the $b$-axis.
\end{abstract}

G lutarimide is an important part of many compounds displaying biological activity. One of the $\alpha$-monosubstituted derivatives, thalidomide, is known for its teratogenic effects ${ }^{1}$ and its central nervous system activity, the latter a property common to many of the substituted glutarimides. ${ }^{2}$<smiles>O=C1CCCC(O)N1</smiles>

In the discussion of the stereochemistry of $\alpha$ - and $\beta$-substituted ${ }^{3,4}$ glutarimides, very little is reported about the possible conformations of the glutarimide ring, which may be either a chair or a flattened form. This has, however, been considered for glutaric anhydrides, ${ }^{5}$ a ring system comparable to glutarimide. Experimental data have led to the suggestion of a half-chair conformation for glutaric anhydrides. ${ }^{6}$ In the crystal structure of $N$-( $\alpha$-glutarimido)-4-bromophthalimide ${ }^{7}$ the glutarimide ring was found to have a half-chair conformation.

A description of the structure of glutarimide itself is presented in this paper. 


\section{EXPERIMENTAL}

Glutarimide crystals of suitable size were obtained by recrystallization from water. They were elongated along $b$, with $(001)$ as the predominant face. Weissenberg photographs showed the crystals to be monoclinic, and the systematic absences lead to the space group $P 2_{1} / c$.

The cell constants were determined by diffractometer measurements of ten moderately high-angle reflections, using $\mathrm{CuK} \alpha$ and $\mathrm{CuK} \beta$ radiation. The unit cell dimensions are $a=10.226(2) \AA, b=7.416(2) \AA, c=7.300(2) \AA, \beta=102.280(9)^{\circ}$. The standard deviations given in parentheses refer to the last figure.

Integrated equi-inclination Weissenberg diagrams $h 0 l \cdots h 6 l$ and $h k 0$ were taken, using Ni-filtered $\mathrm{Cu} K \alpha$ radiation. In all, 937 independent reflections were strong enough to be measured, while 137 were given $1 / 4 I_{\min }$-values. Most of the intensities were measured on a Hilger and Watts photometer, but the weaker ones were estimated visually. The different. layers were put on the same scale by means of common reflections, obtained by rotation about the $b$ and $c$ axes. No corrections have been made for absorption or secondary extinction effects.

When a Picker four-circle automatic diffractometer became available, a new set of intensity data was collected with MoK $\alpha$ radiation. A crystal of size $0.25 \times 0.28 \times 0.25 \mathrm{~mm}$ was used. Reflections out to $2 \theta=65^{\circ}$ were measured by $\theta / 2 \theta$ scan. Of the 1678 reflections recorded, 904 were unobserved, using a cut-off limit of $2.5 \delta$. The data were corrected for secondary extinction.

The atomic form factors used were those of Hanson et al. All programs applied are written or revised for CDC 3300 by T. Dahl, F. Gram, P. Groth, B. Klewe and C. Rømming. ${ }^{\circ}$

\section{DETERMINATION OF THE STRUCTURE}

The intensities were statistically adjusted to an absolute scale, and a preliminary temperature factor, $B=1.7 \AA^{2}$, was used in the calculation of unitary structure factors. The distribution of $|U|$ values was favourable, as 26 reflections had $|U|>0.40$ and six $|U|>0.50$. Three origin-fixing signs and two signs for structure invariants gave 13 more signs by Harker-Kasper inequalities. These 18 signs were used in a sign-determination program, and 158 additional signs were determined. The corresponding three dimensional Fourier map had eight peaks in the asymmetric unit. Two of these were higher than the rest and were considered to correspond to the oxygen atoms.

\section{REFINEMENT}

The coordinates obtained from the Fourier map and the preliminary scale and temperature factor were used as starting parameters in a full-matrix least squares refinement based on the film data. The weighting scheme

$$
\begin{aligned}
& W=\mathrm{A} 1\left(F_{\mathrm{o}}\right) \mathrm{B}^{1} \text { for } F_{\mathrm{o}} / \leq / \mathrm{FB} \\
& W=\mathrm{A} 2\left(F_{\mathrm{o}}\right) \mathrm{B}^{2} \text { for } F_{\mathrm{o}} />/ \mathrm{FB}
\end{aligned}
$$

was used, with $\mathrm{Al}=10.0, \mathrm{~A} 2=31.65, \mathrm{~B} 1=-0.5$, and $\mathrm{FB}=10.0$. After three cycles of isotropic refinement, anisotropic thermal parameters were introduced. A three-dimensional difference Fourier map then yielded the position of the $N$-hydrogen atom and, less clearly, of four of the others. The coordinates of the remaining two hydrogens were calculated assuming tetrahedral $\mathrm{C}-\mathrm{H}$ 
bonds of length $1.03 \AA$. Additional refinements including positional parameters and isotropic temperature factors for the hydrogen atoms were then carried out. In the last two cycles of refinement, the 11 strongest reflections, probably suffering from extinction, were excluded, while the 137 non-observed were included. These were given constant weight $W=\mathrm{Al} / 3(W=1 / \sigma)$. The final $R$-factor was $8.2 \%$.

The parameters from the final refinement above were used in a further refinement, based on the diffractometer data. Only the 774 observed reflections were included in the calculations. The final $R$-value was $6.2 \%\left(R_{w}=\right.$ $5.2 \%$ ). A check of the 176 signs originally determined showed no discrepancies.

The fractional atomic coordinates and anisotropic thermal parameters are given in Table 1, and observed and calculated structure factors in Table 2. Table 1. Positional and thermal parameters $\left(B_{\mathrm{ij}} \times 10^{5}\right)$ with estimated standard

\begin{tabular}{|c|c|c|c|c|c|c|c|c|c|}
\hline Atom & $x$ & $y$ & $z$ & $B_{11}$ & $B_{22}$ & $B_{33}$ & $B_{12}$ & $B_{13}$ & $B_{23}$ \\
\hline C1 & 0.11108 & 0.55051 & 0.21615 & 842 & 1245 & 1938 & 24 & 590 & 253 \\
\hline \multirow{3}{*}{$\mathrm{C2}$} & & & & 32 & 59 & 68 & 71 & 73 & 109 \\
\hline & 0.20165 & 0.39458 & 0.21087 & 1031 & 1198 & 3063 & 218 & 1031 & 159 \\
\hline & & & & 39 & 65 & 108 & 83 & 100 & 131 \\
\hline \multirow[t]{2}{*}{ C3 } & 0.30997 & 0.43151 & 0.10515 & 859 & 1553 & 4380 & 427 & 1418 & -564 \\
\hline & & & & 40 & 75 & 132 & 90 & 113 & 160 \\
\hline \multirow[t]{2}{*}{$\mathrm{C4}$} & 0.37944 & 0.60384 & 0.16333 & 802 & 1948 & 2852 & 155 & 1014 & 160 \\
\hline & & & & 34 & 78 & 89 & 81 & 95 & 138 \\
\hline \multirow[t]{2}{*}{ C5 } & 0.28745 & 0.76012 & 0.16371 & 733 & 1690 & 1584 & -200 & 543 & -268 \\
\hline & & & 35 & 32 & 70 & 62 & 70 & 68 & 100 \\
\hline \multirow[t]{2}{*}{ Ol } & -0.00187 & 0.53665 & 0.24409 & 854 & 1386 & 3933 & -203 & 1915 & 139 \\
\hline & 20 & 25 & 32 & 24 & 42 & 61 & 52 & 60 & 95 \\
\hline \multirow[t]{2}{*}{$\mathrm{O} 2$} & 0.31843 & 0.91548 & 0.14523 & 1052 & 1523 & 2883 & -805 & 1195 & 29 \\
\hline & & 27 & 29 & 26 & 51 & 59 & 54 & 57 & 82 \\
\hline \multirow[t]{2}{*}{ NI } & 0.16058 & 0.71933 & 0.18956 & 705 & 1054 & 2293 & 118 & 862 & 147 \\
\hline & 22 & 31 & 30 & 25 & 45 & 60 & 57 & 62 & 83 \\
\hline \multirow{2}{*}{ H1 } & 0.1060 & 0.8075 & 0.2017 & 3.9 & & & & & \\
\hline & & & 37 & 0.7 & & & & & \\
\hline \multirow{2}{*}{$\mathrm{H} 2$} & 0.1469 & 0.3005 & 0.1629 & 4.6 & & & & & \\
\hline & 29 & 45 & 41 & 0.8 & & & & & \\
\hline \multirow[t]{2}{*}{ H3 } & 0.2473 & 0.3789 & 0.3409 & 8.4 & & & & & \\
\hline & & 56 & 58 & 1.2 & & & & & \\
\hline \multirow[t]{2}{*}{ H4 } & 0.2560 & 0.4619 & -0.0381 & 12.8 & & & & & \\
\hline & 50 & & 72 & 1.5 & & & & & \\
\hline \multirow[t]{2}{*}{ H5 } & 0.3688 & 0.3317 & 0.1288 & 5.2 & & & & & \\
\hline & & & 40 & 0.8 & & & & & \\
\hline \multirow[t]{2}{*}{ H6 } & 0.4254 & 0.5871 & 0.3016 & 5.9 & & & & & \\
\hline & & & 46 & 0.9 & & & & & \\
\hline \multirow[t]{2}{*}{ H7 } & 0.4434 & 0.6467 & 0.0900 & 6.9 & & & & & \\
\hline & 35 & 49 & 49 & 0.9 & & & & & \\
\hline
\end{tabular}

\footnotetext{
${ }^{a}$ The $B_{i j}$ are the thermal parameters in the expression: $\exp \left[-\left(B_{11} h^{2}+B_{22} k^{2}+B_{33} l^{2}+B_{12} h k+\right.\right.$
} $\left.\left.+B_{13} h l+B_{23} k l\right)\right]$. For numbering of atoms, see Fig. 1 .

Acta Chem. Scand. 25 (1971) No. 2 
Table 2. Observed and calculated structure factors. The columns are $h, k, l, F_{\mathrm{o}}$ and $F_{\mathrm{c}}$.

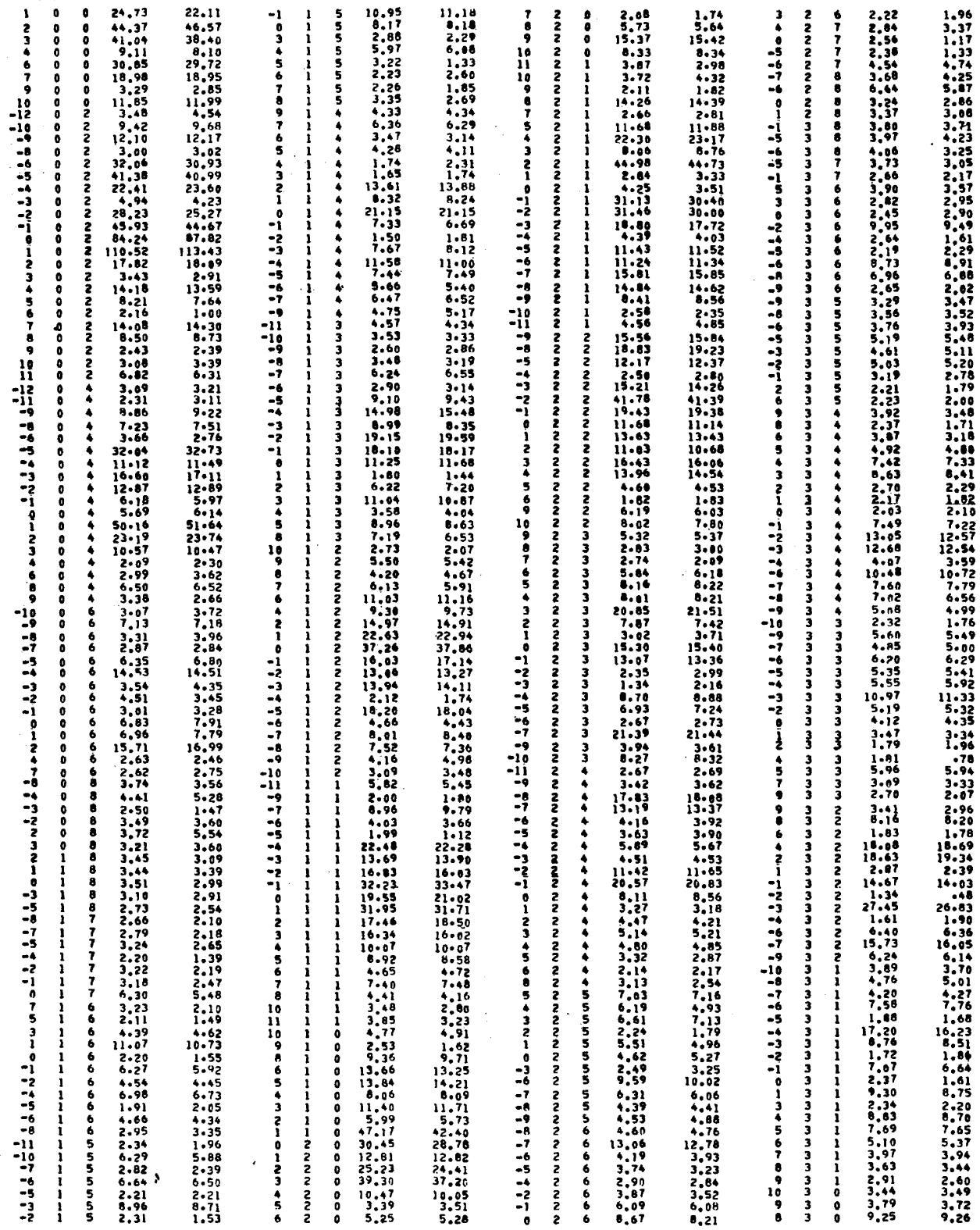

Acta Chem. Scand. 25 (1971) No. 2 
Table 2. Continued.

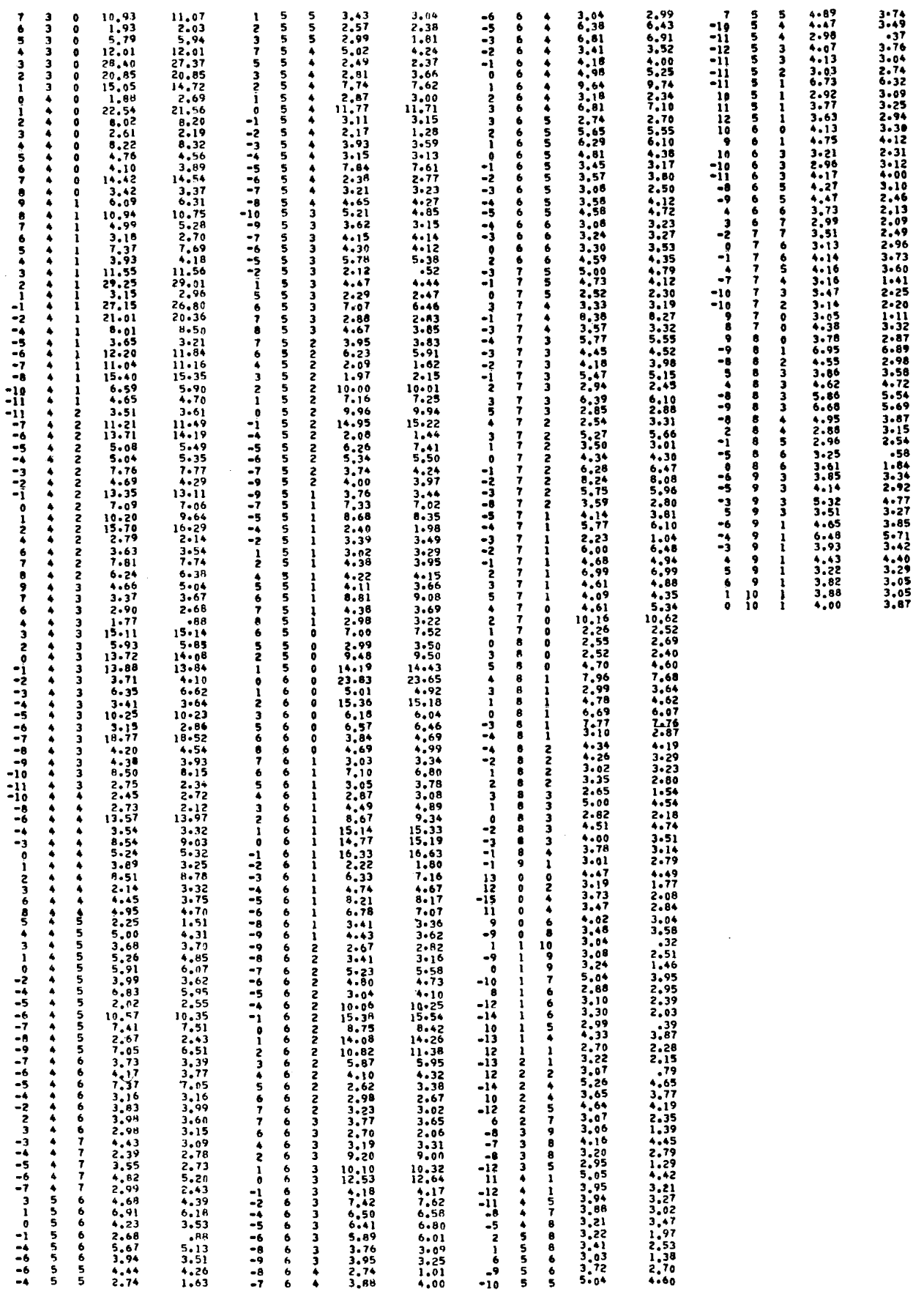

Acta Chem. Scand. 25 (1971) No. 2 


\section{THERMAL MOTIONS}

The principal axes of the thermal vibration ellipsoids for the carbon, nitrogen, and oxygen atoms were calculated from the temperature parameters given in Table 1. Root mean square amplitudes and the corresponding $B$ values for the atomic anisotropic thermal vibrations along the principal axes are given in Table 3, as well as the components of the amplitudes along the crystal axes.

The anisotropic thermal vibration parameters of Table 1 were used in an

Table 3. R.m.s. amplitudes and the corresponding $B$-values along the principal axes of the thermal vibrational ellipsoids and the components of these along the crystal axes.

\begin{tabular}{|c|c|c|c|c|c|}
\hline \multirow{2}{*}{$\begin{array}{l}\text { Atom } \\
\mathrm{Cl}\end{array}$} & \multirow{2}{*}{$\begin{array}{c}\begin{array}{c}\text { R.m.s. } \\
\text { amplitude } \\
\AA\end{array} \\
0.225\end{array}$} & \multirow{2}{*}{$\frac{\begin{array}{l}B \\
\AA^{2}\end{array}}{4.00}$} & \multicolumn{3}{|c|}{$\begin{array}{c}\text { Components of the amplitudes } \\
\text { along the crystal axes } \\
\AA\end{array}$} \\
\hline & & & 0.0476 & 0.0466 & 0.2254 \\
\hline & 0.205 & $\mathbf{3 . 3 3}$ & 0.2057 & -0.0065 & 0.0017 \\
\hline & 0.184 & 2.68 & 0.0022 & -0.1802 & 0.0390 \\
\hline \multirow{3}{*}{ C2 } & 0.281 & 6.25 & 0.0810 & 0.0146 & $0.286 \theta$ \\
\hline & 0.225 & 4.00 & 0.2159 & 0.0452 & -0.0184 \\
\hline & 0.180 & 2.57 & 0.0382 & -0.1764 & 0.0067 \\
\hline \multirow[t]{3}{*}{ C3 } & 0.337 & 8.98 & 0.0758 & -0.0356 & 0.3432 \\
\hline & 0.232 & 4.23 & 0.1760 & 0.1534 & 0.0151 \\
\hline & 0.183 & 2.65 & -0.1186 & 0.1359 & 0.0158 \\
\hline \multirow{3}{*}{ C4 } & 0.272 & 5.84 & 0.0812 & 0.0321 & 0.2755 \\
\hline & 0.233 & 4.29 & 0.0233 & 0.2292 & -0.0306 \\
\hline & 0.193 & 2.94 & -0.1880 & 0.0265 & 0.0132 \\
\hline \multirow[t]{3}{*}{ C5 } & 0.223 & 3.91 & 0.0728 & -0.1971 & 0.0905 \\
\hline & 0.198 & 3.10 & 0.0284 & 0.0784 & 0.1858 \\
\hline & 0.189 & 2.81 & 0.1809 & 0.0458 & -0.0088 \\
\hline \multirow[t]{3}{*}{01} & 0.322 & 8.21 & 0.1295 & 0.0051 & 0.3240 \\
\hline & 0.202 & 3.23 & -0.0886 & 0.1798 & 0.0150 \\
\hline & 0.172 & 2.35 & 0.1437 & 0.0791 & -0.0307 \\
\hline \multirow{3}{*}{$\mathrm{O} 2$} & 0.276 & 6.00 & 0.1353 & -0.0331 & 0.2685 \\
\hline & 0.246 & 4.79 & -0.1624 & $\mathbf{0 . 1 5 3 7}$ & 0.0743 \\
\hline & 0.172 & 2.35 & 0.1051 & 0.1331 & -0.0159 \\
\hline \multirow[t]{3}{*}{$\mathbf{N}$} & 0.244 & 4.71 & 0.0819 & 0.0175 & 0.2474 \\
\hline & 0.183 & 2.64 & 0.1641 & 0.0639 & -0.0258 \\
\hline & 0.169 & 2.26 & 0.0610 & -0.1580 & 0.0043 \\
\hline
\end{tabular}

analysis of the rigid body motion of the molecule, where the $S$-tensor was included to account for correlations of libration and translation. ${ }^{10}$ The results are presented in Table 4. It is seen that translational vibrations of the molecule are essentially isotropic, whereas its librations are rather anisotropic. The maximum librational motion is approximately a $9^{\circ}$ oscillation about an axis lying in the $a b$-plane. The r.m.s. discrepancy between observed and calculated atomic vibration tensor $U_{\text {ij }}$ is 0.0029 (Table 4) and supports the assumption of regarding the molecule as an oscillating rigid body. Corrections of fractional coordinates are listed in Table 5. 
Table 4. Results of the rigid body analysis.

In the orthogonal system, where the axes $J_{1}, J_{2}, J_{3}$ are defined by: $J_{1}\left\|a, J_{2}\right\| b, J_{3} \| c^{*}$. E.s.d. of component of $L$ are given in parentheses in units of last digit shown.

$$
L=\left\{\begin{array}{rrr}
152(13) & 89(12) & -20(9) \\
& 134(11) & -9(8) \\
& & 38(6)
\end{array}\right\} \times 10^{-4} \mathrm{rad}^{2}
$$

\begin{tabular}{ccccr}
\hline & \multirow{2}{*}{ R.m.s. amplitude } & \multicolumn{3}{c}{ Direction cosines } \\
& & $J_{1}$ & \multicolumn{1}{c}{$J_{3}$} \\
\hline \multirow{4}{*}{$L$} & $8.77^{\circ}$ & -0.7406 & -0.6633 & 0.1077 \\
& $4.27^{\circ}$ & -0.6080 & 0.7296 & 0.3131 \\
& $3.33^{\circ}$ & -0.2862 & 0.1664 & -0.9436 \\
$T^{a}$ & $0.196 \AA$ & -0.3779 & 0.2287 & 0.8971 \\
& $0.184 \AA$ & -0.8772 & -0.3984 & -0.2680 \\
& $0.174 \AA$ & 0.2961 & -0.8882 & 0.3512
\end{tabular}

In the orthogonal system $L_{1}, L_{2}, L_{3}$, defined by the principal axes of the libration tensor $L$.

Displacement of libration axes from intersecting

Effective screw translation

$$
\begin{array}{lr}
\text { Parallel to } L_{1} & -0.618 \AA \\
\text { Parallel to } L_{2} & 0.785 \AA \\
\text { Parallel to } L_{3} & -0.096 \AA
\end{array}
$$

$$
\begin{array}{lr}
\text { Parallel to } L_{1} & 0.005 \AA \\
\text { Parallel to } L_{2} & 0.015 \AA \\
\text { Parallel to } L_{3} & -0.033 \AA
\end{array}
$$

\begin{tabular}{|c|c|c|c|c|c|c|}
\hline Atom & $\Delta x$ & $\sigma(x)$ & $\Delta y$ & $\sigma(y)$ & $\Delta z$ & $\sigma(z)$ \\
\hline Cl & -57 & 28 & 2 & 35 & 27 & 37 \\
\hline C2 & 44 & 34 & $-14 \tilde{9}$ & 42 & 23 & 58 \\
\hline C3 & 74 & 33 & -141 & 47 & -57 & 65 \\
\hline C4 & 105 & 30 & -82 & 43 & 1 & 58 \\
\hline C5 & 17 & 25 & -75 & 41 & 7 & 35 \\
\hline 01 & -103 & 20 & 34 & 25 & 34 & 32 \\
\hline 02 & -2 & 19 & 144 & $\mathbf{2 7}$ & -18 & 29 \\
\hline $\mathrm{N}$ & -64 & 22 & 105 & 31 & 7 & 30 \\
\hline
\end{tabular}

$$
\left(\overline{\Delta U_{\mathrm{ij}}{ }^{2}}\right)^{\frac{1}{2}}=0.0029 \AA
$$

${ }^{a} T$ is the reduced translation tensor.

Table 5. Corrections in fractional atomic coordinates due to libration compared with e.s.d. of the coordinates. (The $\Delta^{\prime}$ 's and $\sigma$ 's are multiplied by $10^{5}$.)

\section{DISCUSSION}

The following discussion of the molecular structure is based on the results from the refinement of diffractometer data, since they have the lowest estimated standard deviations. Interatomic distances and angles are given in Table

Acta Chem. Scand. 25 (1971) No. 2 
Table 6. Distances and angles with e.s.d. in parentheses.

\begin{tabular}{|c|c|c|c|}
\hline Distance & $(\AA)$ & Angle & $\left(^{\circ}\right)$ \\
\hline $\mathrm{Cl}-\mathrm{C} 2$ & $1.487(4)$ & $\mathrm{C} 2-\mathrm{Cl}-\mathrm{N}$ & $116.9(2)$ \\
\hline $\mathrm{C} 2-\mathrm{C} 3$ & $1.504(5)$ & $\mathrm{C} 1-\mathrm{C} 2-\mathrm{C} 3$ & $113.7(3)$ \\
\hline C3-C4 & $1.480(4)$ & $\mathrm{C} 2-\mathrm{C} 3-\mathrm{C} 4$ & $111.8(3)$ \\
\hline C4-C5 & $1.493(4)$ & $\mathrm{C} 3-\mathrm{C} 4-\mathrm{C} 5$ & $114.0(3)$ \\
\hline $\mathrm{C} 5-\mathrm{N}$ & $1.384(3)$ & $\mathrm{C} 4-\mathrm{C} 5-\mathrm{N}$ & $116.1(3)$ \\
\hline $\mathrm{Cl}-\mathrm{N}$ & $1.380(3)$ & $\mathrm{C} 5-\mathrm{N}-\mathrm{C} 1$ & $126.9(2)$ \\
\hline $\mathrm{Cl}-\mathrm{O} 1$ & $1.219(3)$ & $\mathrm{N}-\mathrm{Cl}-\mathrm{Ol}$ & $119.3(2)$ \\
\hline $\mathrm{C} 5-\mathrm{O} 2$ & $1.210(3)$ & $\mathrm{O} 1-\mathrm{C} 1-\mathrm{C} 2$ & $123.8(3)$ \\
\hline $\mathrm{Nl}-\mathrm{Hl}$ & 0.88 (3) & $\mathrm{C} 4-\mathrm{C} 5-\mathrm{O} 2$ & $124.0(3)$ \\
\hline $\mathrm{C} 2-\mathrm{H} 2$ & 0.92 & $\mathrm{O} 2-\mathrm{C} 5-\mathrm{N}$ & $119.9(3)$ \\
\hline $\mathrm{C} 2-\mathrm{H} 3$ & $0.97 \quad(4)$ & & \\
\hline $\mathrm{C} 3-\mathrm{H} 4$ & $1.10(5)$ & & \\
\hline C3-H5 & $0.95 \quad(3)$ & & \\
\hline $\mathrm{C} 4-\mathrm{H} 6$ & 1.03 & & \\
\hline $\mathrm{C} 4-\mathrm{H} 7$ & 0.98 (4) & & \\
\hline $\mathrm{N}-\mathrm{Ol}^{\prime}$ & $2.957(3)$ & & \\
\hline
\end{tabular}

6 and those corrected for librational effects in Fig. 1. The standard deviations have been calculated from the last full-matrix least squares cycle, not taking the e.s.d. of the cell parameters into account.

The conformation of the molecule might be described as a half-chair, with C3 $0.58 \AA$ out of the essentially coplanar system, formed by the five other

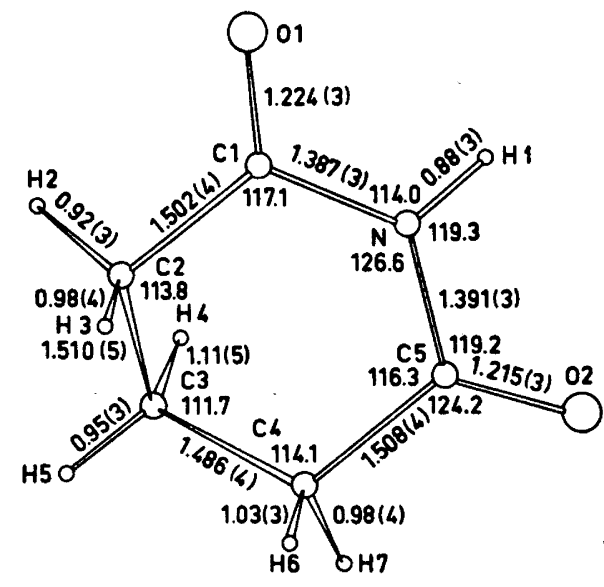

Fig. 1. Bond lengths and angles in glutarimide corrected for libration.

atoms of the glutarimide ring. Deviations from least squares planes are given in Table 7. The atom $\mathrm{Ol}$ is significantly out of plane 1 , while 02 is not. The distances to least squares plane 2 indicate a slight bending of the $\mathrm{Cl}=01$ bond, possibly associated with the formation of the hydrogen bond $01 \cdots \mathrm{H}-\mathrm{N}$. 
Table 7. Departures from least-squares planes.

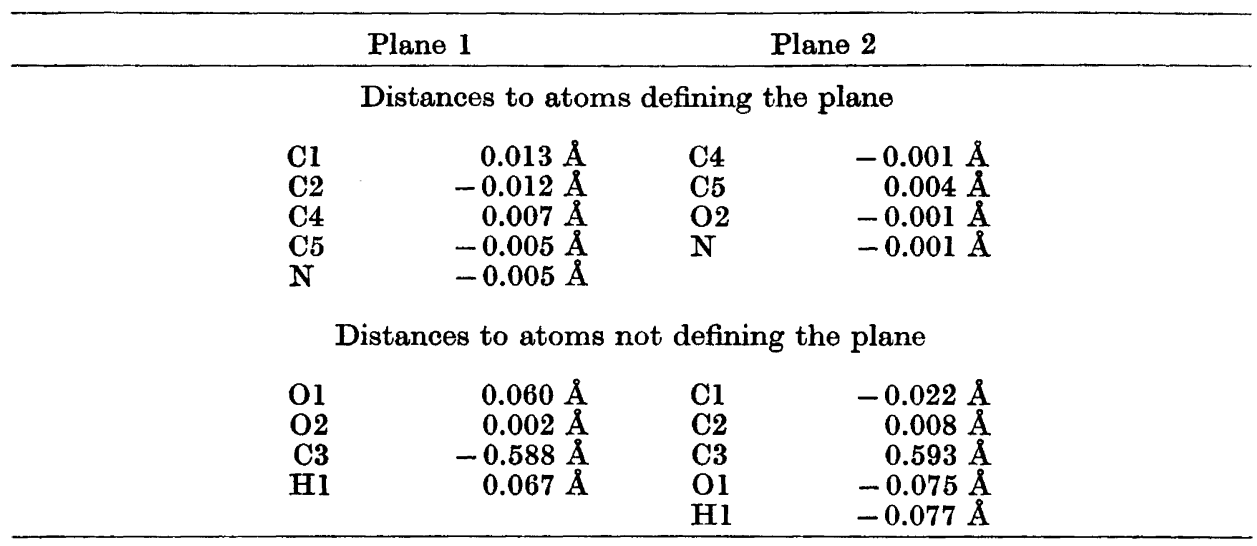

The chemically equivalent bonds, $\mathrm{N}-\mathrm{Cl}, \mathrm{N}-\mathrm{C} 5$ and $\mathrm{Cl}-\mathrm{C} 2, \mathrm{C} 4-\mathrm{C} 5$, have within each pair a difference in bond length of less than 1.5 $\sigma$. Their mean values, $1.389 \AA$ and $1.505 \AA$, differ a little more than $3 \sigma$ from the corresponding distances in 5-ethyl-5-(1-methylbutenyl)-barbituric acid;11 i.e., the $\mathrm{N}-\mathrm{C}$ bond is $0.019 \AA$ longer, and the $\mathrm{C}\left(s p^{2}\right)-\mathrm{C}\left(s p^{3}\right)$ bond $0.019 \AA$ shorter in glutarimide. They are, however, consistent with other observations of bonds which involve trigonal carbon. ${ }^{12,13}$

The two $\mathrm{C}=\mathrm{O}$ bonds have normal lengths, with $\mathrm{Cl}-010.009 \AA$ longer than $\mathrm{C} 5-02$.

The two $\mathrm{C}\left(s p^{3}\right)-\mathrm{C}\left(s p^{3}\right)$ bonds have a mean value of $1.498 \AA$. The apparent shortening of these bonds is not considered to be real and is probably due to an independent thermal vibration of the $\mathrm{C} 3$ atom nearly perpendicular to the plane of the molecule, the main component of the greatest r.m.s. amplitude for C3 being $0.34 \AA$ in the direction of the $c$-axis. This may be taken as an indication of a certain conformational lability, and the assumption of a rigid body is possibly not valid for this molecule, in spite of the satisfactory value of the r.m.s. discrepancy between atomic vibration tensor components.

There are no significant deviations between equivalent angles. The ring angles at $\mathrm{C} 2$ and $\mathrm{C} 4$ are slightly greater than the tetrahedral angle, while at $\mathrm{Cl}$ and $\mathrm{C} 5$ they are less than $120^{\circ}$. At $-\mathrm{Cl}-\mathrm{NH}-\mathrm{C} 5-$ the ring angles are much the same as those found for a similar group in dihydrothymine. ${ }^{14}$ There is a significant difference between the angles at the $\mathrm{C}=\mathrm{O}$ bonds, a feature observed earlier.?

There is one intermolecular distance shorter than normal van der Waals separation, namely $\mathrm{N} \cdots \mathrm{O} 1$ of length $2.94 \AA$. This corresponds to a hydrogen bond $\mathrm{N}-\mathrm{H} \cdots \mathrm{Ol}$, which is nearly linear, the angle at the hydrogen atom being $171^{\circ}$.

The carbonyl group $\mathrm{C} 5=02$ is neither taking part in hydrogen bonding nor involved in dipole-dipole ${ }^{15}$ interactions. The shortest distances from 02 to hydrogen atoms in neighboring molecules are $2.66 \AA(\mathrm{H} 3)$ and $2.67 \AA(\mathrm{H} 4)$.

Acta Chem. Scand. 25 (1971) No. 2 


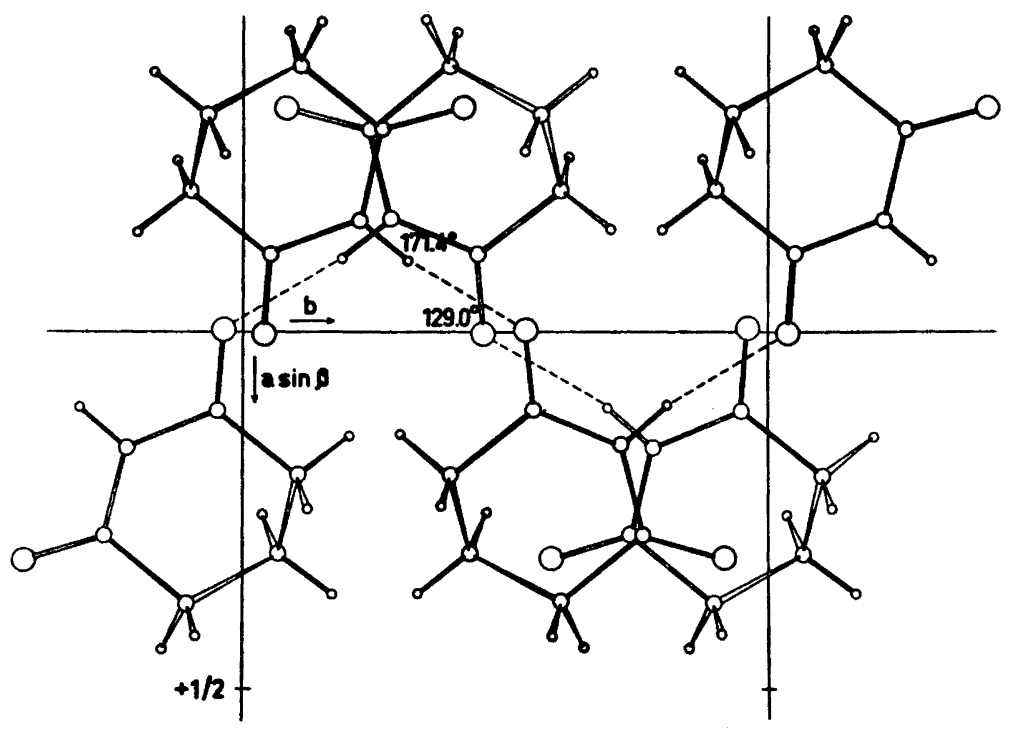

Fig. 2. The structure viewed along the c-axis. Broken lines indicate hydrogen bonds.

In the crystal structures of substituted glutarimides, ${ }^{3,7}$ dimers are formed by $\mathrm{N}-\mathrm{H} \cdots \mathrm{O}$ bonds around centers of symmetry. This arrangement is also observed for other molecules possessing the $-\mathrm{CO}-\mathrm{NH}$ group. ${ }^{16}$ The hydrogen bonding in glutarimide (Fig. 2), however, links the molecules in zigzag chains running parallel to the $b$-axis.

Acknowledgement. The author wishes to thank Norges almenvitenskapelige forsknings$r d d$ for financial support, and Professor Sven Furberg for helpful discussions and interest. in the work.

\section{REFERENCES}

1. Keberle, H., Schmid, R., Faigle, J. W., Fritz, H. and Lowstalot, P. Bull. Schweiz. Acad. Med. Wiss. 22 (1966) 134.

2. Laycock, G. M. and Shulman, A. Nature 213 (1967) 995.

3. Bonaminco, M., Coppola, F. and Gioconello, G. Gazz. Chim. Ital. 91 (1961) 193.

4. Johnson, F., Starkovsky, N. A., Paton, A. C. and Carlson, A. A. J. Am. Chem. Soc. 88 (1966) 149.

5. Le Févre, R. J. W. and Sundaram, A. J. Chem. Soc. 19624009.

6. Bruice, T. C. and Bradbury, W. C. J. Am. Chem. Soc. 87 (1965) 4838.

7. Petersen, C. S. Acta Chem. Scand. 23 (1969) 2389.

8. Hanson, H. P., Herman, F., Lea, J. D. and Skillman, S. Acta Cryst. 17 (1964) 1040.

9. Dahl, T., Gram, F., Groth, P., Klewe, B. and Rømming, C. Acta Chem. Scand. To be published.

10. Schomacher, V. and Trueblood, K. N. Acta Cryst. B 24 (1968) 63.

11. Craven, B. M. and Cusatis, C. Acta Cryst. B 25 (1969) 2291. 
12. Karle, J. and Karle, I. L. J. Am. Chem. Soc. 89 (1967) 804.

13. Bartell, L. S. and Bonham, R. A. J. J. Chem. Phys. 32 (1960) 824.

14. Furberg, S. and Jensen, L. H. J. Am. Chem. Soc. 90 (1968) 470.

15. Bolton, W. Nature 201 (1964) 987.

16. Okaya, Y. Acta Cryst. B 25 (1969) 2257.

Received June 15, 1970.

Acta Chem. Scand. 25 (1971) No. 2 